\title{
Rapid determination of 129 in large-volume water samples using rotary evaporation preconcentration and accelerator mass spectrometry measurement
}

\author{
Li, Jing; Zhang, Luyuan; Hou, Xiaolin; Cheng, Peng; Chen, Ning; Yu, Xia; Liu, Qi; Fan, Yukun
}

Published in:

Journal of Radioanalytical and Nuclear Chemistry

Link to article, DOI:

10.1007/s10967-018-6180-y

Publication date:

2018

Document Version

Peer reviewed version

Link back to DTU Orbit

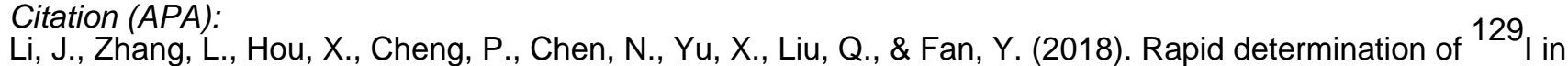
large-volume water samples using rotary evaporation preconcentration and accelerator mass spectrometry measurement. Journal of Radioanalytical and Nuclear Chemistry, 318(3), 2355-2361.

https://doi.org/10.1007/s10967-018-6180-y

\section{General rights}

Copyright and moral rights for the publications made accessible in the public portal are retained by the authors and/or other copyright owners and it is a condition of accessing publications that users recognise and abide by the legal requirements associated with these rights.

- Users may download and print one copy of any publication from the public portal for the purpose of private study or research.

- You may not further distribute the material or use it for any profit-making activity or commercial gain

- You may freely distribute the URL identifying the publication in the public portal 
1 Rapid determination of iodine-129 in large-volume water samples using rotary

2 evaporation preconcentration and accelerator mass spectrometry measurement Jing Li ${ }^{1,4}$, Luyuan Zhang ${ }^{1,3^{*}}$, Xiaolin Hou ${ }^{1,2,3}$, Peng Cheng ${ }^{1,3}$, Ning Cheng ${ }^{1}$, Xia Yu ${ }^{1,4}$, Qi Liu ${ }^{1}$, Yukun Fan ${ }^{1}$

$5{ }^{1}$ State Key Laboratory of Loess and Quaternary Geology, Shaanxi Key Laboratory of

6 Accelerator Mass Spectrometry and Application, Xi' an AMS Center, Institute of Earth

7 Environment, Chinese Academy of Sciences, $X i^{\prime}$ an 710061, China

$8{ }^{2}$ Center for Nuclear Technologies, Technical University of Denmark, Risø Campus,

$9 \quad$ Roskilde 4000, Denmark

103 Open Studio for Oceanic-Continental Climate and Environment Changes, Pilot

11 National Laboratory for Marine Science and Technology (Qingdao), Qingdao 266061,

12 China

$13{ }^{4}$ University of Chinese Academy of Science, Beijing 100049, China

15 E-mail: zhangly@ieecas.cn; houxl@ieecas.cn

\section{Abstract}

17 A rapid method using rotary evaporation combined with accelerator mass spectrometry

18 (AMS) measurement, was developed for the determination of ${ }^{129} \mathrm{I}$ in large-volume water

19 samples. The parameters including water bath temperature, $\mathrm{pH}$, concentration volume

20 and reducing reagent, were thoroughly optimized. The chemical yield of iodine under the 
21 optimal conditions is between 98.8 and $100.7 \%$. Compared to the direct evaporation, the

22 enrichment time can be shortened by five times. The measured ${ }^{129} \mathrm{I} /{ }^{127} \mathrm{I}$ ratios for the

23 environmental water samples are in good agreement with those previously reported

24 values, suggesting this method is accurate, roubust and suitable for ${ }^{129}$ I determination in 25 large water samples.

\section{Keywords}

$27{ }^{129}$ I, Large-volume, Water samples, Rotary evaporation, Accelerator mass spectrometry

\section{Introduction}

29 Iodine has only one stable isotope, ${ }^{127} \mathrm{I}$ and the only long-lived radionuclide is ${ }^{129} \mathrm{I}$

30 (half-life of $15.7 \mathrm{Ma}$ ) [1]. ${ }^{129} \mathrm{I}$ is naturally generated via cosmic ray reactions with xenon

31 in the upper atmosphere, spontaneous fission of ${ }^{238} \mathrm{U}$ and thermal neutron-induced fission

32 of ${ }^{235} \mathrm{U}$ in the earth (with a total inventory of $250 \mathrm{~kg}$ in the environment).

33 The sources of ${ }^{129} \mathrm{I}$ in the environment are currently dominated by human activities,

34 with a total inventory of approximately $6100 \mathrm{~kg}$ released mainly by reprocessing of

35 nuclear fuel as of $2009[2,3]$. The anthropogenic ${ }^{129} \mathrm{I}$ has dispersed to large area, ${ }^{129} \mathrm{I} /{ }^{127} \mathrm{I}$

36 ratios in the environment have increased by 1 to 6 orders of magnitude compared to the

37 level in the pre-nuclear age [4-6]. The conservative behavior in oceans and the

38 physicochemical properties of iodine, as well as the long half-life, make ${ }^{129}$ I ideal for

39 many applications, such as tracing the movement and exchange of water masses in the

40 seas [7, 8], tracing the atmospheric behavior and process of iodine [9], providing 
41 knowledge on geochemical cycling of stable iodine [10,11], tracing the migration of

42 organic matter and age dating of marine geological events between 2 and $80 \mathrm{Ma}$ [12-15].

43 Natural ${ }^{129} \mathrm{I}$ is ideal as a hydrologic tracer owing to being soluble and highly mobile

44 in any hydrologic environment [16]. Fabryka-Martin et al. [16] have presented ${ }^{129}$ I data in

45 ground water samples collected from the Great Artesian Basin, Australia. Along with

46 other hydrogeological evidence, this work suggests large-scale mixing of waters between

47 Cretaceous and Jurassic formations, intrusion of atmospheric iodine to the groundwater

48 and in-situ production of ${ }^{129} \mathrm{I}$ from an underlying formation significantly higher in

49 uranium content. Despite this high potential, applications of ${ }^{129} \mathrm{I}$ in hydrogeological

50 system have so far been limited, because it generally needs large-volume water samples.

51 At least $1 \mathrm{mg}$ of stable iodine $\left({ }^{127} \mathrm{I}\right)$ is required for a measurement, but the environment

52 concentration of ${ }^{127} \mathrm{I}$ is very low, for example, only $1-10 \mu \mathrm{g} / \mathrm{L}$ of iodine are present in

53 meteoric, surface and ground water [17]. A large amount of sample is also needed for the

54 analysis of pre-nuclear samples. For instance, the analysis of a freshwater sample with

$55{ }^{127} \mathrm{I}$ concentration of $5 \mu \mathrm{g} / \mathrm{L}$, and an ${ }^{129} \mathrm{I} /{ }^{127} \mathrm{I}$ ratio of $10^{-12}$, requires at least $10 \mathrm{~L}$ sample to

56 obtain a reliable measurement results. Thus, pre-concentration of iodine from water

57 samples is necessary. The methods are mainly anion exchange chromatography, direct

58 evaporation by heating and rotary evaporation. Anion exchange chromatography is

59 relatively complicated, time-consuming with more than $12 \mathrm{~h}$ for $10 \mathrm{~L}$ water sample, and

60 suffer from low iodine recovery of about 50-87\% [18]. Direct evaporation at sub-boiling

61 conditions is conventionally used, giving a high iodine recovery ( $>90 \%)$ but also taking a

62 long time. For instance, it takes more than $20 \mathrm{~h}$ to concentrate a water sample from $5 \mathrm{~L}$ to

$631 \mathrm{~L}[19,20]$. Rotary evaporation method is operated under pressure for continuous 
64 distillation of volatile solvents, with the advantage of being fast and efficient. This

65 method has been used for freshwater samples from the orange county aquifer system,

66 California, and 40 rivers of the USA, Canada and Western Europe [21-23]. However, it is

67 not clear so far whether the rotary evaporation process cause iodine a loss, and to what

68 extent it will influence the chemical yield of iodine.

69 This work aims to investigate the influence and corresponding mechanisms of the

70 various rotary evaporation parameters on the recovery rate of iodine, and to obtain

71 optimal operation conditions for rapid determination of ${ }^{129} \mathrm{I}$ in large-volume water

72 samples. Finally, the optimized experimental conditions were applied to the

73 determination of ${ }^{129} \mathrm{I}$ in several environmental water samples.

\section{Experimental}

\section{Samples, chemicals and instruments}

76 Four water samples were analyzed in this study. Two rainfall samples were collected

77 on the roof of the Xi'an Accelerator Mass Spectrometry Center $\left(34^{\circ} 13^{\prime} 25.23^{\prime \prime} \mathrm{N}\right.$,

$\left.781^{\circ} 59^{\prime} 58.89^{\prime \prime} \mathrm{E}\right)$ on 8 th December, 2015, and stored in PE containers in dark until

79 analysis. A lake water sample was collected from a public garden in the center of Xi'an

$80 \quad\left(34^{\circ} 15^{\prime} 17^{\prime \prime} \mathrm{N}, 108^{\circ} 58^{\prime} 38^{\prime \prime} \mathrm{E}\right)$ on 2nd September, 2017, and stored in an airtight

81 polyethylene container. An underground water sample was collected in Hancheng of

82 Shaanxi province $\left(35^{\circ} 28^{\prime} 45.9^{\prime \prime} \mathrm{N}, 110^{\circ} 23^{\prime} 41.1^{\prime \prime} \mathrm{E}\right)$, and stored in dark until analysis.

83 All chemical reagents used in this work are of analytical grade, mainly including

$84 \mathrm{NaHSO}_{3}, \mathrm{HNO}_{3}, \mathrm{NaNO}_{2}, \mathrm{AgNO}_{3}, \mathrm{~K}_{2} \mathrm{~S}_{2} \mathrm{O}_{8}$ and $\mathrm{NaOH}$ purchased from Sinopharm

85 Chemical Reagent Co., Ltd (China). Iodine carrier with an ${ }^{129} \mathrm{I} /{ }^{127} \mathrm{I}$ atomic ratio of $2 \times 10^{-14}$ 
86 was obtained from Woodward Company (USA). ${ }^{129}$ I standard solution (NIST-SRM-

87 4949C from the National Institute of Standard and Technology, Gaithersburg, MD, USA)

88 was used to prepare ${ }^{129}$ I standards for the AMS measurement. $\mathrm{Na}^{125}$ I solution (Chengdu

89 Gaotong isotope corporation, China) was used as a tracer. Niobium powders (325 mesh, 90 99.9\%) was purchased from Alfa Aesar Company (Ward Hill, MA, USA). All solutions

91 were prepared using deionized water of $18.2 \mathrm{M} \Omega / \mathrm{cm}$, produced by Cascada TM Lab 92 Water System (Pall Life Sciences, USA).

93 The rotary evaporation system consists of a rotary evaporator (RE-52AA, Shanghai

94 Yarong Biochemical Instrument Factory, China), a circulating vacuum pump (SHB, 95 Zhengzhou Great Wall science and technology co. Ltd) and a low-temperature coolant 96 circulation pump (DLSB-5/20, Zhengzhou great wall science and technology co. Ltd). A 97 gamma counter (Model FJ2021, Xi'an Nuclear Instrument Factory, China) was for ${ }^{125}$ I 98 decay counting for the calculation of the chemical yield. A 3 MV Tandetron AMS 99 (HEVV, The Netherlands) at the Xi'an AMS Center was employed to determine ${ }^{129}$ I. An 100 inductively coupled plasma mass spectrometry (ICP-MS) (Agilent 8800, USA) was used 101 to measure stable ${ }^{127} \mathrm{I}$.

\section{Iodine enrichment using rotary evaporation}

103 In a first experiment 1L deionized water was transferred to a rotary evaporator. 500

$104 \mathrm{~Bq}$ of ${ }^{125} \mathrm{I}$ was added, and then deionized water was preconcentrated by rotary vacuum 105 distillation. In this work, the concentration process was optimized by investigating the 106 effect of various parameters, including water bath temperature $\left(50-80{ }^{\circ} \mathrm{C}\right), \mathrm{pH}$ of sample 107 solution (7-13), reductant concentration (0-10 $\mathrm{mmol} / \mathrm{L})$ and final concentration volume 
108 (10-120 mL). After concentration, $1 \mathrm{~mL}$ of water samples was taken to count ${ }^{125} \mathrm{I}$ for

109 calculating the chemical yield of iodine. Three replicates were done for each experiment.

\section{Separation of iodine from samples}

111 Water samples were filtered through a $0.45 \mu \mathrm{m}$ membrane to remove the suspended

112 particulate matter. $1 \mathrm{~mL}$ of the filtered sample was taken for the determination of total

113 iodine $\left({ }^{127} \mathrm{I}\right)$. Large-volume water samples $(1-5 \mathrm{~L})$ were preconcentrated by the rotary

114 evaporation system. After iodine enrichment, $\mathrm{K}_{2} \mathrm{~S}_{2} \mathrm{O}_{8}$ was added to a final concentration

115 of $30 \mathrm{~g} / \mathrm{L}$. The sample was then incubated at $60^{\circ} \mathrm{C}$ for $20 \mathrm{~h}$ to decompose organic

116 substances, and for converting organic iodine into inorganic form [24]. The samples were

117 transferred to a separation funnel for solvent extraction. $1 \mathrm{mg}$ of iodine carrier, $200 \mathrm{~Bq}$ of

$118{ }^{125} \mathrm{I}$ tracer and $2-3 \mathrm{~mL}$ of $1 \mathrm{~mol} / \mathrm{L} \mathrm{NaHSO}_{3}$ were added. After thoroughly mixing, 3.0

$119 \mathrm{~mol} / \mathrm{L} \mathrm{HNO}_{3}$ was added to adjust the $\mathrm{pH}$ to 1 to 2 , and $15 \mathrm{~mL}$ of $\mathrm{CCl}_{4}$ was added, and 2-4

$120 \mathrm{~mL}$ of $1 \mathrm{~mol} / \mathrm{L} \mathrm{NaNO}_{2}$ solution to oxidize iodide to $\mathrm{I}_{2}$. The formed molecular iodine $\left(\mathrm{I}_{2}\right)$

121 was then extracted into the $\mathrm{CCl}_{4}$ phase by shaking. After transferring $\mathrm{CCl}_{4}$ from the

122 funnel to a beaker, a second $10-15 \mathrm{~mL}$ of new $\mathrm{CCl}_{4}$ was added to the funnel to extract the

123 remaining iodine. The $\mathrm{CCl}_{4}$ phases were combined and transferred to a new separation

124 funnel. $10 \mathrm{~mL}$ of $\mathrm{H}_{2} \mathrm{O}$ and $0.5-1.0 \mathrm{~mL}$ of $0.1 \mathrm{~mol} / \mathrm{L} \mathrm{NaHSO}_{3}$ solution were added for

125 back extraction of iodine. The extraction and back-extraction process was repeated once

126 more. After removal of the $\mathrm{CCl}_{4}$ phase, the water phase was transferred to a $15 \mathrm{~mL}$

127 centrifuge tube. ${ }^{125} \mathrm{I}$ in the separated solution in the centrifuge tube was counted using the

128 gamma detector, and the recovery of iodine in the separation procedure was calculated by

129 comparing the ${ }^{125} \mathrm{I}$ count in the samples to those in a ${ }^{125} \mathrm{I}$ standard solution with the same

130 volume. After ${ }^{125} \mathrm{I}$ measurement, $1.0 \mathrm{~mL}$ of $1.0 \mathrm{~mol} / \mathrm{L} \mathrm{AgNO}_{3}$ was added to the separation 
131 solution in the centrifuge tube to precipitate iodide as AgI. The separation AgI was

132 washed using deionized water, and the separated $\mathrm{AgI}$ was dried at $60^{\circ} \mathrm{C}$ for $2-3 \mathrm{~h}$. After

133 ground to fine powder, 3 times (by weight) niobium powder was weight and mixed with

134 the AgI powder, the mixture was pressed into a copper holder for the AMS measurement 135 of ${ }^{129} \mathrm{I} /{ }^{127}$ I ratio.

136 Determination of ${ }^{129} \mathbf{I}$ and ${ }^{127} \mathbf{I}$

$137{ }^{129} \mathrm{I} /{ }^{127} \mathrm{I}$ atomic ratios in the prepared targets were measured by AMS using the $3 \mathrm{MV}$ 138 tandem AMS system (HVEE) at the Xi'an AMS center. $\mathrm{I}^{-}$ions sputtered from the ion

139 source were accelerated and passed through a stripper to strip off several electrons of 140 iodine. $\mathrm{I}^{5+}$ was chosen for the measurement, consequently ${ }^{127} \mathrm{I}^{5+}$ was measured as charges 141 (current) using a Faraday cup and ${ }^{129} \mathrm{I}^{5+}$ was measured using a gas ionization detector. 142 The sample was measured for 6 cycles, and each sample for 5 min in each cycle.

143 Total iodine $\left({ }^{127} \mathrm{I}\right)$ concentrations in water samples were measured by ICP-MS using 144 an Agilent 8800 ICP-MS (Thermal Electron Corporation), under hot plasma conditions 145 (RF of $1500 \mathrm{~W}$ ), with the $\mathrm{Xt}$ interface. $10 \mathrm{~mL}$ filtered water was diluted by an appropriate 146 factor using $0.5 \%$ Tetramethylammonium hydroxide (TMAH) solution, and ${ }^{133} \mathrm{Cs}^{+}(\mathrm{CsCl})$ 147 was spiked as internal standard to a concentration of $2.0 \mathrm{ng} / \mathrm{mL}$.

\section{$148 \quad$ Results and discussion}

\section{Effect of water bath temperature on recovery and evaporation time}

150 Water bath temperature is one of the parameters to determine distillation speed, which 151 was investigated from $50^{\circ} \mathrm{C}$ to $80^{\circ} \mathrm{C}$ by using deionized water with addition of ${ }^{125} \mathrm{I}$ tracer. 
152 The results show that chemical yield of iodine increases with temperature increasing from $15350^{\circ} \mathrm{C}$ to $60^{\circ} \mathrm{C}$, and then decreases from $60^{\circ} \mathrm{C}$ to $80^{\circ} \mathrm{C}$, with a peak value of $95.3 \pm 1.43 \%$ at $15460^{\circ} \mathrm{C}$ (Fig. 1). The chemical reaction rate of iodide oxidation in aqueous solution is 155 affected by the temperature [25]. The oxidation rate will increase with increasing 156 temperature. Therefore, the lower recovery of iodine at higher temperature might be 157 attributed to the formation of volatile iodine species (e.g. HIO, $\mathrm{I}_{2}$ ) [26, 27]. In contrast, a 158 relatively lower recovery was observed at $50^{\circ} \mathrm{C}$, which might be attributed to long 159 evaporation time [28], approximately two times longer as that at $60^{\circ} \mathrm{C}$ (Fig. 1). The 160 evaporation time to concentrate from $1 \mathrm{~L}$ to $100 \mathrm{~mL}$ is greatly reduced from $155.0 \pm 3.0$ $161 \mathrm{~min}$ at $50^{\circ} \mathrm{C}$ to $58.5 \pm 1.5 \mathrm{~min}$ at $80^{\circ} \mathrm{C}$. For $60^{\circ} \mathrm{C}$, with optimal recovery of iodine, about $16273.5 \pm 1.1 \mathrm{~min}$ is necessary. Base on both evaporation time and iodine recovery, $60^{\circ} \mathrm{C}$ is 163 selected as the optimal water bath temperature.

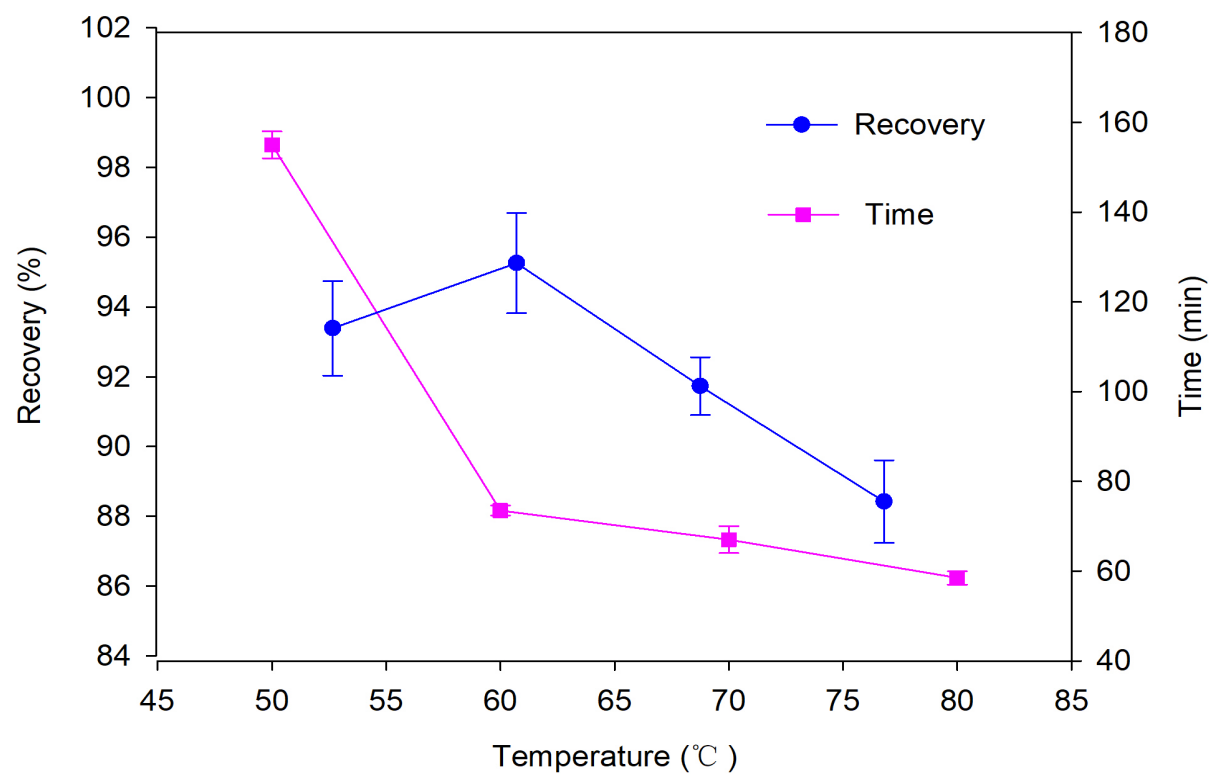


Journal of Radioanalytical and Nuclear Chemistry

165 Fig.1 Effect of water bath temperature on iodine recovery and evaporation time.(The sample is deionized water with addition of ${ }^{125} \mathrm{I}$; Initial water volume, $1 \mathrm{~L}$; Final concentrated volume, $100 \mathrm{~mL})$.

\section{Effect of $\mathbf{p H}$ on recovery of iodine}

169 Even with the optimal water bath temperature $\left(60^{\circ} \mathrm{C}\right)$, there is still a $5 \%$ loss of iodine,

170 which might be attributed to the $\mathrm{pH}$ of sample solution and formation of volatile iodine

171 species. The experiment above was conducted using a neutral solution. Iodide is more 172 stable under alkaline conditions [29], thus, the effect of solution $\mathrm{pH}$ is investigated by 173 adjusting from 7 to 13.

174 The results show recovery of iodine in the range of $94-95 \%$ and no significant

175 change was found (Table 1). Increase in $\mathrm{pH}$ and decrease in the redox potential could 176 reduce the formation of volatile iodine [30-33]. However, in alkaline solution, the 177 electrode potential of $\mathrm{O}_{2}$ is higher than the electrode potential of $\mathrm{I}^{-}$, so iodine redox 178 reaction can still occur (Eq.(1))[3, 33]. Since the experiment was carried out under

179 vacuum, volatile iodine species escape more easily, and the chemical reaction was push 180 to the right of the equation. Therefore, $\mathrm{pH} 7$ was selected as the optimal $\mathrm{pH}$ value.

$$
2 \mathrm{I}^{-}+1 / 2 \mathrm{O}_{2}+\mathrm{H}_{2} \mathrm{O} \longleftrightarrow \mathrm{I}_{2}+2 \mathrm{OH}^{-}
$$

\section{Effect of reductant concentration on recovery of iodine}

183 Alternatively, addition of a reducing agent may inhibit iodine loss caused by formation of

184 volatile species. The effects of $\mathrm{NaHSO}_{3}$ addition on the recovery of iodine were

185 investigated in a water bath at $60^{\circ} \mathrm{C}$ and $\mathrm{pH}=7$. The reductant concentrations in the sample 186 solution were set at $1 \mathrm{mmol} / \mathrm{L}, 3 \mathrm{mmol} / \mathrm{L}, 5 \mathrm{mmol} / \mathrm{L}, 10 \mathrm{mmol} / \mathrm{L}$. As shown in Fig.2, with 
187 the increase of reducing agent from 0 to $5 \mathrm{mM}$, the recovery of iodine increased from $18895.3 \pm 1.4 \%$ to $99.5 \pm 0.8 \%$, followed by a slightly decrease when the reducing agent 189 concentration was more than $5 \mathrm{mmol} / \mathrm{L}$. The results suggest that addition of reductant

190 could effectively inhibit the oxidation of $\mathrm{I}^{-}$to $\mathrm{HIO} / \mathrm{I}_{2}$ and avoid iodine loss. During the 191 experiment, it was observed that when the reductant concentration increases, a large 192 amount of bubbles appear during distillation. Therefore, it can be speculated that the 193 decrease in recovery might be attributed to decomposition of $\mathrm{NaHSO}_{3}$ to produce $\mathrm{SO}_{2}$ 194 gas, which promotes the reaction of $\mathrm{I}^{-}$in the solution with $\mathrm{O}_{2}$ in the distillation flask and 195 thus reduces the recovery of iodine.

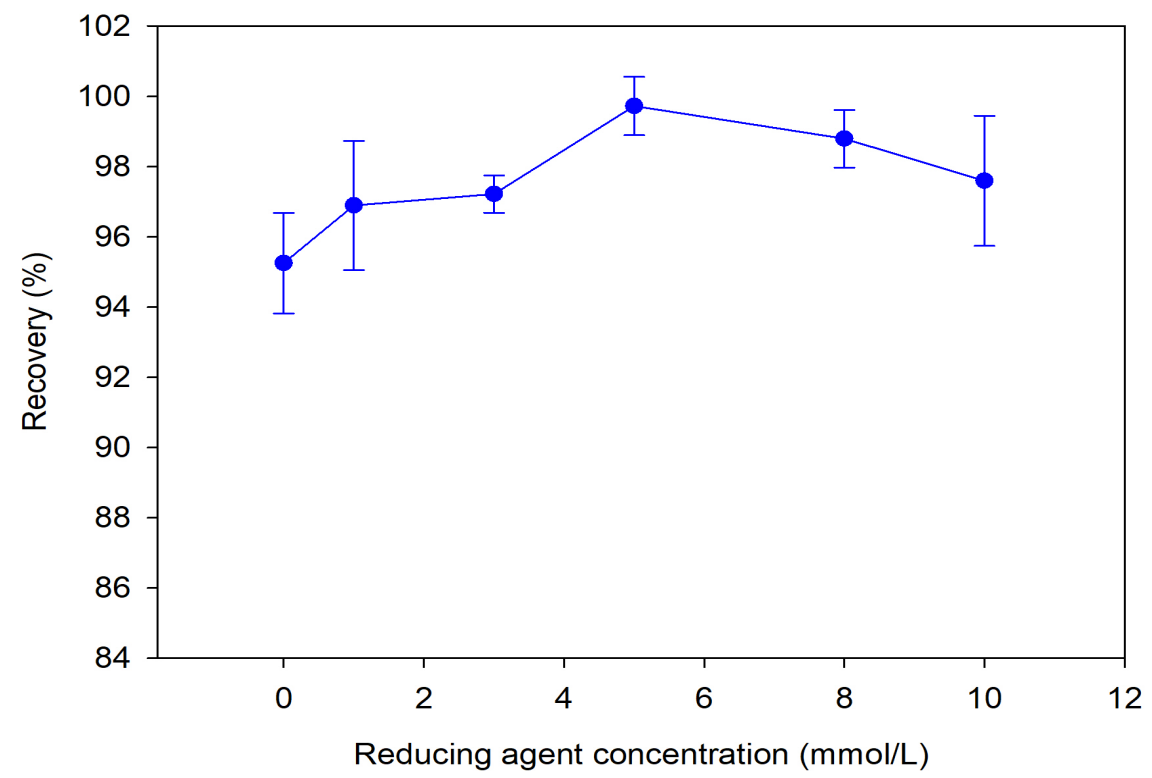

197 Fig.2 Effect of reductant concentration on iodine recovery. (Sample: deionized water;

198 Water bath temperature, $60^{\circ} \mathrm{C}$; Initial water volume, $1 \mathrm{~L}$; Final concentrated volume, 100 $\mathrm{mL} ; \mathrm{pH}=7$ ). 
201 The water was concentrated to a final volume of $120 \mathrm{~mL}, 100 \mathrm{~mL}, 50 \mathrm{~mL}, 20 \mathrm{~mL}$ and 10

$202 \mathrm{~mL}$ at a water bath temperature of $60^{\circ} \mathrm{C}, \mathrm{pH}$ of 7 and a $\mathrm{NaHSO}_{3}$ concentration of 5

$203 \mathrm{mmol} / \mathrm{L}$. As shown in Table 1, when the volume was concentrated from $120 \mathrm{~mL}$ to 100

$204 \mathrm{~mL}$, there is basically no iodine loss $(99.7 \pm 1.3 \%$ and $99.5 \pm 0.8 \%)$. When the final

205 concentrated volume was reduced from $100 \mathrm{~mL}$ to $10 \mathrm{~mL}$, iodine recovery gradually

206 decreased. This is because the time required for concentrating the water sample to a

207 smaller volume gradually increases. In a same water bath temperature, the longer the

208 time, the lower the efficiency of iodine recovery [28]. In summary, $100 \mathrm{ml}$ is selected as

209 the optimal final concentrated volume.

210 Table 1 Effect of pH (Group 1) and concentrated volume (Group 2) on iodine recovery*

\begin{tabular}{|c|c|c|c|c|c|c|}
\hline \multicolumn{4}{|c|}{ Group 1} & \multicolumn{3}{|c|}{ Group 2} \\
\hline pH & $\begin{array}{c}\text { Initial } \\
\text { volume } \\
\text { (mL) }\end{array}$ & $\begin{array}{l}\text { Concentrated } \\
\text { volume }(\mathrm{mL})\end{array}$ & $\begin{array}{c}\text { Recovery } \\
(\%)\end{array}$ & $\begin{array}{l}\text { Concentrated } \\
\text { volume } \\
(\mathrm{mL})\end{array}$ & $\begin{array}{c}\text { Initial } \\
\text { volume } \\
\text { (mL) }\end{array}$ & $\begin{array}{c}\text { Recovery } \\
(\%)\end{array}$ \\
\hline 7 & 1000 & 100 & $95.3 \pm 1.4$ & 10 & 1000 & $95.2 \pm 0.5$ \\
\hline 8 & 1000 & 100 & $94.4 \pm 0.8$ & 20 & 1000 & $95.6 \pm 1.4$ \\
\hline 11 & 1000 & 100 & $94.0 \pm 0.6$ & 50 & 1000 & $97.3 \pm 1.1$ \\
\hline 13 & 1000 & 100 & $95.3 \pm 1.3$ & 100 & 1000 & $99.5 \pm 0.8$ \\
\hline & & & & 120 & 1000 & $99.7 \pm 1.3$ \\
\hline
\end{tabular}

$211 *$ Group 1: Effect of $\mathrm{pH}$ on iodine recovery. (Sample: Deionized water; Water bath temperature,

$21260^{\circ} \mathrm{C} ; \mathrm{pH}$ adjustment is performed by $\mathrm{NaOH}$ ); Group 2: Effect of concentrated volume on iodine

213 recovery (Sample: Deionized water; Water bath temperature, $60^{\circ} \mathrm{C} ; \mathrm{pH}=7$; Reductant concentration, $2145 \mathrm{mmol} / \mathrm{L})$. 
Journal of Radioanalytical and Nuclear Chemistry

216 With the optimal experimental conditions obtained above, environmental fresh water

217 samples were analyze for ${ }^{129} \mathrm{I}$, including rain, lake and ground water samples.

218 The chemical yields of iodine among these samples are shown in Table 2. At the

219 same initial volume (1 L), a slightly lower recovery of iodine of $93.3-95.5 \%$ was

220 observed for the real environmental water samples in comparison to deionized water

221 ( $99.5 \pm 0.8 \%)$. This difference might be caused by the presence of organic matter in rain

222 and lake water. The content of dissolved organic matter in rainwater was reported to be

$2230.33-31.58 \mathrm{mg} / \mathrm{L}$ [34]. In the process of rotary evaporation, the organic matter in the

224 water sample reacts with the reducing agent to consume a part of the reducing agent,

225 weakened the reducing effect of the reducing agent on $\mathrm{I}_{2}$, so that the actual iodine

226 recovery of the water sample is lower than that of the deionized water. For ground water,

227 a recovery of $89.0 \pm 2.4 \%$ was achieved for a $5 \mathrm{~L}$ sample. The $5 \mathrm{~L}$ water was equally

228 divided into five aliquots. The first $1 \mathrm{~L}$ water was preconcentrated to a volume of 200

$229 \mathrm{~mL}$, and then added another $1 \mathrm{~L}$ water sample until the total of $5 \mathrm{~L}$ water was finally

230 concentrated to $100 \mathrm{~mL}$. For each $1 \mathrm{~L}$ water sample, the recovery of iodine can be

231 calculated to be $97.7 \%$ by extracting the quintic root, which is comparable with the

232 recovery for deionized water. This also confirms the influence of organic matter in real

233 water samples. In addition, rain water samples were subjected to experiments comparing

234 recovery with and without addition of reducing agent. The recoveries are $95.4 \pm 0.4 \%$ and

$23593.3 \pm 1.3 \%$ in the presence and absence of reductant, respectively. The result shows that

236 the addition of reducing agent slightly improves the recovery of iodine in real water

237 samples. Iodine in less than $1 \mathrm{~L}$ rainwater samples can be directly separated and purified 
238 by solvent extraction $[3,35,36]$. However, for samples over $1 \mathrm{~L}$, the low phase volume

239 ratio in the extraction process results in recovery of less than $85 \%$, and is highly organic

240 solvent-consuming, time-consuming and labor-intensive. In this case, the sample is

241 firstly concentrated and then subjected to solvent extraction or direct precipitation. The

242 advantage is obvious: small sample size, easy to operate, shortened time, less organic

243 solvent used and high recovery of iodine $(>90 \%)$.

244 As shown in Table 2, the traditional heating plate evaporation method takes more

245 than 20 hours to concentrate $5 \mathrm{~L}$ water samples to $1 \mathrm{~L}$, rotary evaporation only 5 hours

246 from $5 \mathrm{~L}$ to $0.1 \mathrm{~L}$, indicating that the rotary evaporation method can greatly reduce

247 sample preparation time at least 4 times.

248 The analytical results of ${ }^{129} \mathrm{I} /{ }^{127} \mathrm{I}$ atomic ratios in two rainwater, one lake water and

249 one ground water samples are shown in Table 2 . The ${ }^{129} \mathrm{I}^{127} \mathrm{I}$ ratios are $(23.5 \pm 2.4) \times 10^{-10}$

250 and $(24.5 \pm 2.5) \times 10^{-10}$ for rain water samples with and without addition of reductant,

251 respectively, $(5.67 \pm 0.28) \times 10^{-10}$ for lake water, and $(0.1 \pm 0.05) \times 10^{-10}$ for ground water.

252 These results are in good agreement with those published in our previous work [19, 20,

253 37], indicating that the rotary evaporation method is accurate, time saving and suitable

254 for ${ }^{129}$ I analysis of large-volume environmental water samples.

255 Table 2 Analytical performance and results of ${ }^{129} \mathrm{I} /{ }^{127} \mathrm{I}$ atomic ratios in environmental

256 water samples.

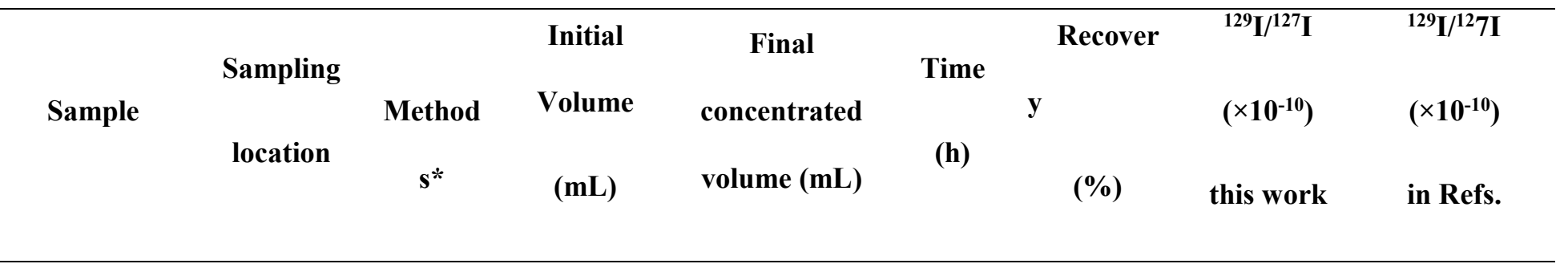




\begin{tabular}{|c|c|c|c|c|c|c|c|c|}
\hline Rain & Xi'an & 1 & 1000 & 100 & 1.2 & $95.4 \pm 0.4$ & $23.5 \pm 2.4$ & $24.6 \pm 2.1^{[37]}$ \\
\hline Rain & Xi'an & 1 & 1000 & 100 & 1.2 & $93.3 \pm 1.3$ & $24.5 \pm 2.5$ & $24.6 \pm 2.1^{[37]}$ \\
\hline Lake water & Xi'an & 1 & 1000 & 100 & 1.2 & $93.4 \pm 1.5$ & $5.68 \pm 0.28$ & $5.74 \pm 0.32$ \\
\hline Ground water & Hancheng & 1 & 5000 & 100 & 5 & $89.0 \pm 2.4$ & $0.10 \pm 0.05$ & $0.11 \pm 0.04^{[20]}$ \\
\hline Rain & Xi'an & 2 & $700-1500$ & $100-300$ & $10-12$ & $91.7-99.5$ & - & _[19] \\
\hline Ground water & Hancheng & 2 & 5000 & 1000 & $>20$ & $92.0-99.9$ & - & _[20] \\
\hline
\end{tabular}

$257 *$ Methods: 1. Rotary evaporation followed with solvent extraction;

258 2. Direct evaporation method using a hot plate below $100{ }^{\circ} \mathrm{C}$.

260 Conclusion

261 In this study, the experimental conditions of water bath temperature, water sample $\mathrm{pH}$

262 and reductant addition are optimized in detail. The results show that when $\mathrm{pH}$ is 7,

263 concentration of reducing agent is $5 \mathrm{mmol} / \mathrm{L}$, water bath temperature is $60{ }^{\circ} \mathrm{C}$, and final

264 concentrated volume is $100 \mathrm{~mL}$, the iodine recovery is as high as $99 \%$ for deionized

265 water and slightly lower (> 93\%) for real environmental water samples. This study also

266 suggests that improper conditions of rotary evaporation will cause iodine loss of $5 \%$ or

267 even up to $15 \%$, which will underestimate ${ }^{129}$ I concentration in environmental water

268 samples. Compared with the traditional low-temperature evaporation method, the rotary

269 evaporation method can effectively shorten the iodine pre-enrichment time by at least

270 four times. Therefore, the rotary evaporation method is feasible and suitable for ${ }^{129} \mathrm{I}$ 
271 analysis in large-volume environmental water samples, and this can serve to broaden ${ }^{129} \mathrm{I}$

272 tracing applications in hydrogeological systems. Furthermore, this method can also be

273 used for reserving large-volume water samples in a smaller sample size.

\section{Author Information}

276 Corresponding author

277 Tel: 0086 029-62336195; Mobile: 00861318601 7212; Email: zhangly@ieecas.cn;

278 houxl@ieecas.cn

280 Acknowledgment

281 Financial support from the National Natural Science Foundation of China (No. 11605207

282 and 91643206), the Technology Foundation for Selected Overseas Chinese Scholar,

283 Department of Human Resources and Social Security of Shaanxi Province, China, and 284 the Ministry of Science and Technology basic project (No. 2015FY110800) are gratefully 285 acknowledged.

\section{$287 \quad$ References}

288 1. Fabryka-Martin JT (1984) Natural Iodine-129 as a ground-water trace.The University 289 of Arizona

290 2. He P, Aldahan A, Possnert G, Hou XL (2013) A summary of global ${ }^{129}$ I in marine 291 waters. Nucl Instrum Methods Phys Res Sect B 294:537-541 
Journal of Radioanalytical and Nuclear Chemistry

292 3. Hou XL, Hansen V, Aldahan A, Possnert G, Lind OC, LujanieneG (2009) A review on 293 speciation of iodine-129 in the environmentaland biological samples. Anal Chim Acta

$294 \quad 632: 181-196$

295 4. Snyder G, Aldahan A, Possnert G (2010) Global distribution and long-term fate of 296 anthropogenic ${ }^{129}$ I in marine and surface water reservoirs. Geochem Geophys Geosyst $297 \quad 11: 1-19$

298 5. Xing S, Hou XL, Aldahan A, Possnert G (2017) Speciation analysis of ${ }^{129}$ I in seawater 299 using coprecipitation and accelerator mass spectrometry and its applications. J Radioanal $300 \quad$ Nucl Chem 311:1-9

301 6. Xing S, Hou XL, Aldahan A, Possnert G, Shi KL, Yi P, Zhou WJ (2015) Iodine-129 in 302 snow and seawater in the Antarctica: Level and Source. Environ Sci Technol 49:66913036700

304 7. Raisbeck GM, Yiou F, Zhou ZQ, Kilius LR (1995) ${ }^{129}$ I from nuclear fuel reprocessing 305 facilities at Sellafield (U.K.) and La Hague (France) potential as an oceanographie tracer. 306 J Mar Syst 6: 561-570

307 8. Hou XL (2004) Application of ${ }^{129}$ I as an environmental tracer. J Radioanal Nucl Chem $308 \quad 262: 67-75$

309 9. López-Gutiérrez JM, Santos FJ, GarcíA-León M, Schnabel C, Synal HA, Ernst T,

310 Szidat S (2004) Levels and temporal variability of ${ }^{129}$ I concentrations and ${ }^{129} \mathrm{I} /{ }^{127} \mathrm{I}$

311 isotopic ratios in atmospheric samples from southern Spain. Nucl Instrum Methods Phys

312 Res Sect B 223-224:495-500 
Journal of Radioanalytical and Nuclear Chemistry

313 10. Snyder G, Fehn U (2004) Global distribution of ${ }^{129}$ I in rivers and lakes: implications

314 for iodine cycling in surface reservoirs. Nucl Instrum Methods Phys Res Sect B 223-

$315 \quad 224: 579-586$

316 11. Muramatsu Y, Yoshida S, Fehn U, Amachi S, Ohmomo Y (2004) Studies with

317 natural and anthropogenic iodine isotopes: iodine distribution and cycling in the global

318 environment. J Environ Radioact 74:221-232

319 12. Fehn U, Moran JE, Teng RTD, Rao U (1994) Dating and tracing of fluids using ${ }^{129} \mathrm{I}$

320 and 36Cl: results from geothermal fluids, oil field brines and formation waters. Nucl

321 Instrum Methods Phys Res Sect B 92:380-384

322 13. Fehn U, Snyder G, Egeberg PK (2000) Dating of pore waters with I-129: Relevance

323 for the origin of marine gas hydrates. Sci 289:2332-2335

324 14. Lu Z, Tomaru H, Fehn U (2008) Iodine ages of pore waters at Hydrate Ridge (ODP

325 Leg 204), Cascadia Margin: Implications for sources of methane in gas hydrates. Earth

326 Planet Sci Lett 267: 654-665

327 15. Moran JE, Fehn U, Hanor JS (1995) Determination of source ages and migration

328 patterns of brines from the U.S. Gulf Coast basin using ${ }^{129}$ I. Geochim Cosmochim Acta

329 59: 5055-5069

330 16. Fabryka-Martin J, Bentley H, Elmore D, Airey PL (1985) Natural iodine-129 as an

331 environmental tracer. Geochim Cosmochim Acta 49:337-347

332 17. Hou XL, Zhou WJ, Chen N, Zhang LY, Liu Q, Luo MY, Fan YK, Liang W, Fu YC

333 (2010) Determination of ultralow level ${ }^{129} \mathrm{I} /{ }^{127} \mathrm{I}$ in natural samples by separation of

334 microgram carrier free iodine and accelerator mass spectrometry detection. Anal Chem

$335 \quad 82: 7713-7721$ 
Journal of Radioanalytical and Nuclear Chemistry

336 18. Park SD, Kim JS, Han SH, Ha YK, Song KS, Jee KY (2009) The measurement of ${ }^{129}$ I

337 for the cement and the paraffin solidified low and intermediate level wastes (LILWs),

338 spent resin or evaporated bottom from the pressurized water reactor (PWR) nuclear

339 power plants. Appl Radiat Isot 67:1676-1682

340 19. Chen N, Zhou WJ, Hou XL, Fan YK, Xian F, Zhang LY, Liu Q, Jiang XH (2017)

341 Level and characteristic of ${ }^{129}$ I of rain samples in Xi'an region, China. J Earth Environ

$342 \quad 8: 327-339$

343 20. Ma XZ, Song Y, Liu SB, Jiang L, Hong F (2013) Origin and evolution of waters in

344 the Hancheng coal seams, the Ordos Basin, as revealed from water chemistry and isotope

$345\left(\mathrm{H}, \mathrm{O},{ }^{129} \mathrm{I}\right)$ analyses. Sci China Earth Sci 56:962-1970

346 21. Schwehr KA, Santschi PH, Moran JE, Elmore D (2005) Near-conservative behavior

347 of I in the orange county aquifer system, California. Appl Geochem 20:1461-1472

348 22. Moran JE, Oktay SD, Santschi PH (2002) Sources of iodine and iodine-129 in rivers.

349 Water Resour Res 38:24-1-24-10

350 23. Moran JE, Schink DR, Oktay S, Santschi PH (1999) Atmospheric dispersal of 129-

351 iodine from nuclear fuel reprocessing facilities. Environ Sci Technol 33:2536-2542

352 24. Dang HJ, Hou XL, Roos P, Nielsen SP (2013) Release of iodine from organic matter

353 in natural water by $\mathrm{K}_{2} \mathrm{~S}_{2} \mathrm{O}_{8}$ oxidation for ${ }^{129} \mathrm{I}$ determination. Anal Methods 5:449-456

354 25. Greene CR, Steinle SE (1959) Conversion of hydrogen iodide to iodine. US

355 26. Zhang LY, Hou XL, Xu S (2015) Speciation Analysis of ${ }^{129}$ I and ${ }^{127}$ I in Aerosols

356 Using Sequential Extraction and Mass Spectrometry Detection. Anal Chem 87:6937-

$357 \quad 6944$

358 27. Paparatto G, Gregorio G (1989) Process for the manufacture of iodine. US 
Journal of Radioanalytical and Nuclear Chemistry

359 28. Zhu HL, Liu LL (2004) Effect of temperature on iodine content in iodized salt.

360 Practical Medical Technology Magazine 11:2054-2054

361 29. Powers D (2000) Insight into the Control of the Release of Iodine, Cesium,Strontium,

362 and Other Fission Products in the Containment by Severe Accident Management.

363 NEA/CSNI/R 9:43-75

364 30. Zhang WN (2012) Studies on Speciation and Influencing Factors of Iodine in

365 Enviornment Water System. Jilin University

366 31. Younus I, Yim MS (2015) Out-containment mitigation of gaseous iodine by alkaline

367 spray insevere accident situation. Prog Nucl 83:167-176

368 32. Luo XZ (1986) A method for monitoring the course of oxidation of iodine ion during

369 radioactive iodination operation. At Energy Sci Technol 20:320-320

370 33. Liu Y, Hans R (1988) Migration chemistry and behaviour of iodine relevant to

371 geological disposal of radioactive wastes. PSI

372 34. Liang J, Jiang T, Wei SQ (2015) Absorption and Fluorescence Characteristics of

373 Dissolved Organic Matter(DOM) in Rainwater and Sources Analysis in Summer and

374 Winter Season. Enviorn Sci 3:888-897

375 35. Zhang LY, Zhou WJ, Hou XL, Chen N, Liu Q, He C, Fan YK, Luo MY, Wang Z, Fu

376 YC (2011) Level and source of ${ }^{129}$ I of environmental samples in Xi'an region, China. Sci

377 Total Environ 409: 3780-3788

378 36. Fan YK, Hou XL, Zhou WJ (2013) Progress on ${ }^{129}$ I analysis and its application in

379 environmental and geological researches. Desalination 321:32-46

380 37. Jiang XH (2017) Study on the Level of Change and Tracing of ${ }^{129}$ I in Precipitation in

381 Xi'an Area. Chinese Academy of Sciences University 
Journal of Radioanalytical and Nuclear Chemistry

382 